\title{
Ao abrigo dos discursos circulantes
}

Mayra Rodrigues Gomes ${ }^{1}$ 


\section{Resumo}

Este artigo traz reflexão sobre os conceitos de discurso e de formação discursiva a partir da obra de Michel Foucault. Tenta apontar suas naturezas por meio de suas relações de inclusão e de complementaridade. As explorações conceituais aqui expostas têm a intenção de esclarecer, relacionar e, sobretudo, encontrar uma forma de expressão mais enxuta para os processos que fundam os discursos na materialidade do mundo.

\section{Palavras-chave}

Enunciado, formação discursiva, discurso circulante.

Abstract

This article brings considerations about the concepts of discourse and of discursive formation from the point of view of Michel Foucault works. It tries to point out their nature through its inclusive and complementary relationships. The conceptual explorations brought here carry the intention of clarify, relate and, above all, find an expression form more concise to the processes that imbed the discourses in the world materiality.

\section{Keywords}

Enunciated, discursive formation, circulating discourse. 


\section{Uma preocupação}

Nas universidades, uma das preocupações de docentes/pesquisadores é a de precisar seus aportes teóricos, delinear suas aplicações e circunscrever o horizonte de inquietações que animam seus trabalhos. Tal medida é tanto mais crucial quanto o campo, por sua própria natureza, convida a um olhar diversificado e pede cruzamento de conceitos e posições transdisciplinares.

É nesse espírito que brotam as considerações aqui apresentadas em torno da noção de discurso, pois, dentre os conceitos centrais aos nossos trabalhos junto ao campo das ciências da linguagem, tanto sob a perspectiva da docência quanto sob a da pesquisa, situa-se o de discurso. Várias definições a ele são dadas, conforme vieses de indagação ou aplicação; a boa parte delas recorremos, justamente conforme as circunstâncias.

O exame desse uso não se esgotaria aqui e, com certeza, em nenhum outro espaço; mesmo assim pretendemos remetê-lo a algum parâmetro que dê conta de cobrir as convergências nas explicações do conceito, ainda que não ignoremos as contraposições, ou as difrações.

Grosso modo, tem-se que um discurso corresponde a um agrupamento de enunciados, mantido por alguma unidade relativa a campo, forma ou conteúdo, por suas regras de construção, pelas estratégias de atualização e por seus efeitos na materialidade do mundo. Sobretudo, é nessa materialidade que ele vem à superfície, ao fazê-la emergir.

Podemos, com certa segurança e como extensão à notação anterior, adotar o entendimento de discurso como um arranjo de enunciados unificados no conjunto pelo compartilhamento de um modo de produção, de um tema/ objeto, de um vocabulário especializado. Em geral é em relação a esses tópicos que se apontam/localizam discursos com referência específica a campos do saber, a posições ideológicas, a posições epistemológicas, a enquadramentos históricos: o discurso da matemática, o discurso marxista, o discurso empirista, o discurso iluminista etc. 
Mas, mesmo em relação a essas instâncias vemos de imediato que cada uma comporta diversos discursos, conforme circunstâncias sóciohistóricas, conforme vetores tomados no interior desses mesmos campos. Talvez, tema e objeto componham, fortemente, uma linha unificadora, ainda que tema e objeto sejam variadamente contornados. Talvez situações contextuais sejam tão ou mais importantes que tema e objeto para a avaliação ou apontamento de um dado discurso.

Essas são questões que permanecem em nosso horizonte, pois ocorre que, em virtude da natureza do campo da comunicação a que estamos filiados, tendemos a interrogar o conceito de discurso sob a perspectiva de seus efeitos, ou melhor, de sua presença/materialização no mundo. Condizentemente, temos que considerá-lo sob o viés das relações de poder, estas por sua vez pensadas em paralelo ao poder de sobredeterminação dos discursos em dada cultura e, ao mesmo tempo, consideradas enquanto as circunstâncias de florescimento, fixação, dispersão e abandono de um discurso.

Ora, esse posicionamento, ainda que tenha um lastro nas metodologias de análise de discurso, assim como todo um manancial dentro das diversas semióticas e da filosofia da linguagem como um todo, nos vincula estreitamente à obra de Michel Foucault, já que a concepção de discurso deste pensador leva em conta as negociações, as fricções de força com que, de que e em que um discurso se desenha.

\section{Sob o olhar de Foucault}

Contudo, Foucault define diferentemente um discurso, a começar pela introdução de uma condição para os enunciados, condição segundo a qual os enunciados não representam unidades primordiais do ponto de vista do sentido, embora representem as formas-base do discurso. 
Um enunciado pertence a uma formação discursiva, como uma frase pertence a um texto, e uma proposição a um conjunto dedutivo. Mas enquanto a regularidade de uma frase é definida pelas leis de uma língua, e a de uma proposição pelas leis de uma lógica, a regularidade dos enunciados é definida pela própria formação discursiva (FOUCAULT, 1997a, p. 135).

Ao conceito de formação discursiva ele reserva uma anterioridade lógica. É no interior de uma formação discursiva que os enunciados são concebíveis, ou melhor, que eles podem encontrar sua existência. Sua significação é rebatimento de um pré-dado de caráter cognitivo já inscrito na formação discursiva.

A título de experiência, pensemos nos enunciados sobre aborto que se colocam em nossa contemporaneidade. Eles formam um conjunto enquanto se delineiam a partir de um longo caminho acumulativo de argumentos em torno dos direitos femininos, da liberdade de escolha, da preservação da saúde (enquanto medicamente assistida e controlada) etc. Tais argumentos se entrecruzam e extraem sua razão de ser de vários enunciados culturalmente estabelecidos, não sem controvérsias ou oposições, que tecem o panorama de nosso entendimento de mundo. A esse conjunto de circunstâncias que pautam os dizeres de uma época como a nossa e se materializam em discursos, devemos a noção de formação discursiva. Mas, nos adiantamos. Retornemos aos passos de um trajeto conceitual.

Compreendendo os enunciados enquanto "viáveis" a partir de uma formação discursiva, a própria noção de discurso será colocada por Foucault em situação condicional.

Chamaremos de discurso um conjunto de enunciados, na medida em que se apoiem na mesma formação discursiva; ele não forma uma unidade retórica ou formal, indefinidamente repetível e cujo aparecimento ou utilização poderíamos assinalar (e explicar, se for o caso) na história; é constituído de um número limitado de enunciados para os quais podemos definir um conjunto de condições de existência (FOUCAULT, 1997a, p. 135). 
Um discurso, dimensão mais ampla em que os enunciados se ajeitam, encontra sua razão de ser numa formação discursiva, também uma dimensão mais ampla do que a de discurso. Nesse caso, é necessário precisar a dimensão e entendimento que podemos ter do que Foucault entende por formação discursiva.

Seguiremos seu caminho que começa justamente pela interrogação sobre o que faz com que os enunciados componham um conjunto, o que lhes agrega em discursos. Tal interrogação, orientada pela procura de critérios para uma análise da materialidade discursiva, leva Foucault a perpassar quatro formas tradicionais nas considerações sobre o agrupamento dos enunciados.

Porém, ao examinar cada uma delas, o eixo unitário a partir do qual elas são colocadas se dilui sempre que se contemplam os casos particulares, ou, como assinalamos anteriormente a título de exemplo, sempre que se constata que um campo, tema ou objeto, comporta vários grupos de enunciados, muitas vezes concomitantemente.

Nesses agrupamentos, para resumir radicalmente a questão, no caso em que se tome um domínio de objeto, Foucault encontrou séries lacunares, no caso de um marcado tipo de enunciado e suas normas, ele encontrou funções heterogêneas, no caso de um alfabeto de noções, ele encontrou conceitos transportados de outros campos, na permanência temática, ele encontrou a possibilidade de ativação de temas incompatíveis ou a introdução de um mesmo tema em conjuntos diferentes.

A título de explicação para as conexões imprevistas nos eixos de agrupamento, tomemos o campo em que trabalhamos. O campo da comunicação é atravessado por diferenciadas perspectivas de conhecimento filiadas a teorias da comunicação e, hoje em dia, pautadas pelas considerações sobre as tecnologias digitais. Diz-se que qualquer grupo de enunciados sobre esse campo que não leve em conta tais tecnologias e desconsidere um movimento de convergência, de resto genericamente bastante detectável, está fadado ao fracasso teórico/compreensivo ou ao fracasso prático/criativo. 
No entanto, vieses clássicos, sempre reformados, coexistem e, mais importante, aquilo que no geral tem sido chamado de cultura da convergência permeia diversos campos, dispersa-se com seus efeitos de sentido sobre toda a produção cultural. Comanda dizeres, como esse que anuncia o fracasso inerente a sua desconsideração, ou seja, instala um pré-dado que se repartirá pelos discursos, portanto, pela materialidade do mundo por eles enunciada.

Daí a ideia de descrever essas dispersões, de pesquisar se entre esses elementos, que seguramente não se organizam como um edifício progressivamente dedutivo, nem como um livro sem medida que se escreveria, pouco a pouco, através do tempo, nem como a obra de um sujeito coletivo, não se poderia detectar uma regularidade: uma ordem em seu aparecimento sucessivo, correlações em sua simultaneidade, posições assinaláveis em um espaço comum, funcionamento recíproco, transformações ligadas e hierarquizadas. Tal análise não tentaria isolar, para descrever sua estrutura interna, pequenas ilhas de coerência; não se disporia a suspeitar e trazer à luz os conflitos latentes; mas estudaria formas de repartição (FOUCAULT, 1997a, p. 43).

Em sua busca metodológica, face à dispersão, Foucault procura e encontra uma unidade transversal e coloca o conceito de formação discursiva para dar conta do que ele detectou nas repartições por campos e para dar conta de que a noção não fosse confundida com outros planos, ou vetores, também eles associados ao conceito de discurso.

No caso em que se puder descrever, entre um certo número de enunciados, semelhante sistema de dispersão, e no caso em que entre os objetos, os tipos de enunciação, os conceitos, as escolhas temáticas, se puder definir uma regularidade (uma ordem, correlações, posições e funcionamentos, transformações), diremos, por convenção, que se trata de uma formação discursiva - evitando, assim, palavras demasiado carregadas de condições e consequências, inadequadas, aliás, para designar semelhante dispersão, tais como "ciência", ou "ideologia", ou "teoria", ou "domínio de objetividade" (FOUCAULT, 1997a, p. 43). 
Na realidade é uma potência de irradiação que marcará a regularidade assinalada em uma formação discursiva e, sobretudo, sua condição enquanto pré-dado. Ora, nesse caso, devemos perguntar sobre a dimensão dada às formações discursivas em relação ao conceito de discurso e em relação a níveis de discursos como colocado pelo próprio Foucault no conjunto de sua obra.

No interior de sua obra a palavra discurso remete ora a processos abrangentes, ora a configurações setoriais. Às vezes, o que importa é sua configuração, mas sempre é importante para Foucault a configuração que um discurso traz, a ordem das coisas que ele instala.

Discursos como a economia, a medicina, a gramática, a ciência dos seres vivos, dão lugar a certas organizações de conceitos, a certos reagrupamentos de objetos, a certos tipos de enunciação, que formam, segundo seu grau de coerência, de rigor e de estabilidade, temas ou teorias... (FOUCAULT, 1997a, p. 71).

\section{Vontade de saber}

Por um lado, os efeitos em temas ou teorias, as próprias organizações ou processos se inscrevem no pré-dado das formações discursivas. Nesse caso, para estabelecermos alguma diferença de nível, diferença que nos interessa em termos de aplicabilidade nos nossos estudos, temos que colocar as noções aqui introduzidas lado a lado com a de vontade de saber, ou vontade de verdade, como colocada por Foucault, porque ela se conecta diretamente com a notação de um pré-dado.

Foucault, em diversos momentos de sua obra, nos lembra que a vontade de verdade é um processo sobredeterminante até mesmo sobre os outros processos de controle dos discursos. Ele alerta para o fato de que ela determina temas, e vieses, portanto objetos, o quadro compreensivo em que estes se encerram, os arranjos possíveis de sua exposição. Assinala que com ela não está em questão a verdade como tal, mas a verdade que se produz e será tida e mantida como tal. 
Daí, enfim, o fato de o ponto importante não ser determinar se essas produções discursivas e esses efeitos de poder levam a formular a verdade do sexo ou, ao contrário, mentiras destinadas a ocultá-lo, mas revelar a "vontade de saber" que lhe serve ao mesmo tempo de suporte e de instrumento (FOUCAULT, 1997b, p.17).

Em relação à vontade de saber e à verdade produzida, podemos dizer que as formações discursivas se orientam por elas, que um discurso/macro, saber de um tempo, sustenta as formações discursivas. Indo um pouco além, no saber constituído há poder investido de forma tal que nele se tende à eliminação de contradiscursos em prol da hegemonia de um discurso abrangente.

Não é à toa que Foucault nos dirá que Mendell dizia a verdade, mas não estava no verdadeiro de seu tempo. A verdade de seu tempo, um macro discurso parceiro do poder constituído (o da ciência, inclusive), retém tudo na malha fina dos dizeres que Ihe são cabíveis.

Por outro lado, se a dispersão também é característica da vontade de saber, porque um discurso como o da ciência, por exemplo, segundo adequação ao da Igreja nos tempos a que Foucault se refere, irradia-se permeando todos os campos. Em contraparida, nas formações discursivas a dispersão se caracteriza pelos vieses diferenciados, pelo espaço dado à subversão de si, pelas rebarbas deixadas, pelos cruzamentos calculáveis, mas também pelos incalculáveis.

Nesse caso, estamos tratando de instâncias que detém a mesma natureza, desde sua unidade nos enunciados até sua composição mais abrangente que nos dá um entendimento do mundo. Temos então que assinalar o fato de que a diferenciação resulta de um tipo de indagação sobre limites/fronteiras dos discursos em meio a uma formação discursiva e o fato de que é a própria formação discursiva que desenha a possibilidade desse limite, como efeito de uma organização de seu campo.

Na realidade, assim posto, ou seja, em termos de processos, não há diferenças de porque se trata de estratégias que se atualizam sempre nas 
formações discursivas e nos discursos que elas determinam e com os quais elas se materializam. À distinção, talvez de grau, se sobrepõem a formação em rede, nos termos em que essa palavra tem sido empregada, hoje em dia, na concepção de hipertexto.

Podemos prosseguir com exemplos, agora testando nossa formulação nas explicações com que Foucault designa a formação dos objetos. A psicopatologia do século XIX fez surgir uma série de objetos, cada um como objeto de observação, objeto de práticas terapêuticas etc.

Havíamos procurado a unidade do discurso junto aos próprios objeto, à sua distribuição, ao jogo de suas diferenças, de sua proximidade ou de seu afastamento (...) Mas entendamos: não são os objetos que permanecem constantes, nem o domínio que formam; nem mesmo seu ponto de emergência ou seu modo de caracterização; mas o estabelecimento de relação entre as superfícies em que podem aparecer, em que podem ser delimitados, analisados e especificados (FOUCAULT, 1997a, p.53-54).

As condições históricas de surgimento de um objeto são complexas e numerosas e se as considerarmos do ponto de vista do campo da comunicação podemos ver esse momento que antecede e acompanha a Segunda Guerra como o ponto em que há relações de superfície, nos discursos, em que a comunicação é apresentada como objeto, em que a ela é designado campo, processos, funções, teorias etc.

Essas relações são estabelecidas entre instituições, processos econômicos e sociais, forma de comportamentos, sistemas de normas, técnicas, tipos de classificação, modos de caracterização; (...) Elas não definem a constituição interna do objeto, mas o que Ihe permite aparecer, justaporse a outros objetos, situar-se em relação a eles, definir sua diferença, sua irredutibilidade e, eventualmente, sua heterogeneidade; enfim, ser colocado em um campo de exterioridade" (FOUCAULT, 1997a, p.51). 
Em alguns casos podemos ver essa exteriorização, que a rigor constrói um objeto: no surgimento da comunicação como campo de estudos (não que ela não existisse ou não se falasse dela anteriormente) temos a emergência de um modo de ser do objeto. O mesmo acontece com o tema aborto que aflora como um "tipo" de objeto, antes condenado a um silêncio tácito, sobre o qual se fala sob uma perspectiva contemplada nas relações de superfície que se tecem contemporaneamente.

Isto significa que não se pode falar de qualquer coisa em qualquer época; não é fácil dizer alguma coisa nova; não basta abrir os olhos, prestar atenção, ou tomar consciência, para que novos objetos logo se iluminem e na superfície do solo, lancem sua primeira claridade (FOUCAULT, 1997a, 51).

Em alguns casos, como naqueles examinados por Foucault em relação à psicopatologia do século XIX, não se trata do afloramento de um modo ou tipo de objeto, mas do próprio objeto. Para voltarmos, novamente, a nossa contemporaneidade, assinalamos a emergência do estresse como entidade, do estressado como modo de ser e de todo um entorno discursivo que pontifica sobre profilaxia e comporta instituições agregadas, incluindo aquelas vinculadas à farmacologia.

As relações discursivas, como se vê, não são internas ao discurso: não ligam entre si os conceitos ou as palavras (...). Mas não são, entretanto, relações exteriores ao discurso (...). Elas estão, de alguma maneira, no limite do discurso; oferecem-Ihe objetos de que ele pode falar (FOUCAULT, 1997a, p.52).

A mesma relação pode ser vista, e até como processo denotativo, na referência a obsessivos compulsivos, que por certo sempre existiram. Não mais uma mania, muito mais como identidade, sob certos aspectos dignificada, ela se unifica em sigla: fulano ou beltrano é portador de TOC. 
Claro que toda essa exploração de caráter conceitual cabe aqui, num artigo com viés acadêmico. Mas, e não é por uma questão de tabu de objeto, ela deixa de ter sua finalidade em alguns espaços de aula por ficarem, na maior parte do tempo, em planos excessivamente abstratos e por comportarem um jogo de remissão que cria ambiguidades.

\section{Das superfícies}

Em virtude de princípios pedagógicos, procuramos maneiras de contornar a remissão e de colocar as palavras e as coisas em termos mais palpáveis. Quanto a isso, ficamos resguardando a afirmação de Foucault quando diz que "Assim, o enunciado circula, serve, se esquiva, permite ou impede a realização de um desejo, é dócil ou rebelde a interesses, entra na ordem das contestações e das lutas, torna-se tema de apropriação ou de rivalidade" (FOUCAULT, 1997a, p.121). Ficamos circulando em torno da ideia de circulação, ponto chave numa formação discursiva.

Um dia prestamos atenção em uma esquecida, por nós, definição de Patrick Charaudeau que, em sua simplicidade, parece comportar todas as dimensões implicadas na noção de formação discursiva e, ao mesmo tempo, apontar para seus componentes.

"O discurso circulante é uma soma empírica de enunciados com visada definicional sobre o que são os seres, as ações, os acontecimentos, suas características, seus comportamentos e os julgamentos a eles ligados" (CHARAUDEAU, 2006, p. 118).

Tudo que é da ordem do pré-dado foi coberto por essa afirmação. Um discurso circula e dispersa-se, repartindo-se em diversos campos de saber, práticos ou teóricos, definindo objetos e, naturalmente, seu modo de ser. Um discurso monta um quadro cognitivo em que perspectivas, ainda que divergentes, encontrarão sua inserção e resolução. 
Um discurso circulante é o que atualiza uma formação discursiva, tornando-a materialidade. Esta se manifesta tanto em um só discurso quanto nos vários que se cruzam e se apoiam nela, em determinado tempo e lugar. Esta se manifesta num entendimento de mundo ao qual nos adequamos e que comporta uma verdade segundo a qual seremos levados a agir.

Foi nesse trajeto que encontramos um modo de localização dos discursos no interior de uma formação, modo que julgamos dar conta, em consideração a uma superfície de relações que os abriga, tanto da superfície quanto da relação. 


\section{Referências}

ChARAUDEAU, Patrick. Discurso das mídias. São Paulo: Contexto, 2006.

FOUCAULT, Michel. A arqueologia do saber. Rio de Janeiro, Forense Universitária, 1997a.

FOUCAULT, Michel. A ordem do discurso. São Paulo, Loyola, 1996.

FOUCAULT, Michel. As palavras e as coisas. São Paulo, Martins Fontes, 1995.

FOUCAULT, Michel. História da sexualidade. Vol. I A vontade de saber. Rio de Janeiro, Edições Graal, 1997b. 